\title{
Brasil-ilha e histórias da literatura: entrevista com Ettore Finazzi-Agrò
}

\author{
BRUNO MAZOLINI DE BARROS \\ Pontifícia Universidade Católica do Rio Grande do Sul - PUCRS
}

T

Ettore Finazzi-Agrò é professor catedrático de Literatura Portuguesa e Brasileira na Faculdade de Ciências Humanas da Universidade de Roma "La Sapienza". Seus estudos envolvem desde a lírica galego-portuguesa e pesquisas relacionadas à épica e à novelística portuguesa do séc. XVI até trabalhos com mitos de descoberta e literatura de viagem. É também pesquisador da obra de Fernando Pessoa, e escreveu, entre outros ensaios, $O$ álibi infinito: o projecto e a prática na poesia de Fernando Pessoa (Lisboa: Imprensa Nacional/Casa da Moeda, 1987). No âmbito da literatura brasileira, conta com estudos sobre Mário de Andrade, Jorge Amado, Guimarães Rosa, Clarice Lispector, Rubem Fonseca, Antônio Callado e Nélida Piñon, entre outros. Entre essas publicações, destacam-se Apocalypsis H.G.: una lettura intertestuale della Paixão segundo G.H. e della Dissipatio H.G. (Roma: Bulzoni, 1984), e Um lugar do tamanho do mundo: tempos e espaços da ficção em João Guimarães Rosa (Belo Horizonte: Ed. UFMG, 2001). Em parceria com Roberto Vecchi, organizou duas coleções de ensaios: Formas e mediações do trágico-moderno: uma leitura do Brasil (São Paulo: Unimarco, 2004) e Travessias do pós-trágico: os dilemas de uma leitura do Brasil (São Paulo: Unimarco, 2006). Sua obra mais recente publicada no Brasil é Entretempos: mapeando a história da cultura brasileira (São Paulo: Ed. Unesp, 2013).

A entrevista com o professor Ettore Finazzi-Agrò, que se desenvolve a partir de apontamentos sobre Entretempos, foi realizada durante a sua participação no XI Seminário Internacional de História da Literatura, no prédio da Faculdade de Letras da Pontifícia Universidade Católica do Rio Grande do Sul, em Porto Alegre, no dia 07 de outubro de 2015. No evento, participou com a conferência de abertura Fantasmagorias do tempo: apagamento da memória e invenção da história no espaço brasileiro e ministrou o minicurso A história literária elou a literatura como história: propostas de leitura do tempo brasileiro.

Bruno MAZOLINi de BARRos - Em termos da gênese do seu estudo Entretempos, qual foi o ponto crucial que modelou a configuração em "rede" que ele possui? De que forma o objeto do seu estudo, e a busca de historicizar o conceito de Brasil como ilha, direcionou para essa configuração? Ou, de outra maneira: por que uma historiografia literária baseada num sequenciamento temporal oitocentista não daria conta do seu objeto de estudo?

ETTORE FinAZZI-AGRò - Na verdade, há uma série de causas que desde o início me levaram a pensar nessa nova tentativa de dar conta da história da cultura brasileira. Uma delas foi justamente a ideia de um Brasil como ilha, que é uma constante dentro da cultura brasileira. Ela aparece logo no início, na famosa Carta do Achamento, e depois retorna por volta da metade do século XVI. Curiosamente, essa imagem do Brasil-ilha vigora e continua funcionando durante séculos. Eu descobri mapas do século XVIII nos quais mais uma vez o Brasil é apresentado como uma ilha.

Havia essa ideia de que os dois grandes rios, o da Prata e o Amazonas, tinham como origem uma enorme lagoa ou um lago central dentro do continente sul-americano, que tinha vários nomes, entre eles Lagoa Dourada. Ora, Lagoa Dourada ligando-se também ao mito do Eldorado, um mito que atravessa a dimensão sul-americana. Não é só um mito ligado ao Peru, é um mito que encontramos 
em vários outros passos da América Meridional. Assim, havia essa ideia de que existia uma enorme bacia central que tinha esse nome Lagoa Dourada, mas também nomes indígenas ou de aparências indígenas, como "upaua", "upama", a partir da qual partia os dois rios que separavam o Brasil do resto do continente americano. É curioso, o imaginário tem um tempo longo, ele não é pontual. A própria denominação do Amazonas vem de um mito que vem lá de Homero, no início da literatura ocidental.

Essa ideia de que o Brasil fosse uma grande ilha é, na verdade, uma ideia que continua funcionando também depois da exploração do território e chega até o século XVII. Ela não funciona somente para os brasileiros, a coroa portuguesa e depois a colônia portuguesa também se interessaram na ideia de uma grande ilha dentro do oceano hispano-americano. Isso tinha um valor político. Se é uma ilha, então ela era toda de direito da coroa portuguesa. Temos que pensar que o Tratado de Tordesilhas, na verdade, entregava a Portugal só uma pequena parte do Brasil. A ideia de que era uma enorme ilha dava a possibilidade de manter o controle desse espaço imenso que era demarcado ao sul pelo Rio da Prata e ao norte pelo Rio Amazonas. Essa ideia da ilha começa a partir da Carta do Achamento, cria um mito Brasil-ilha, reaparece no século XVI, mas atravessa toda a cultura brasileira até a atualidade.

Isso aparece, por exemplo, em autores de histórias da literatura, como o Silvio Romero e o Ronald de Carvalho, mas também aparece em vários outros lugares essa ideia de que o Brasil, a cultura brasileira e a identidade brasileira são específicos, e exatamente por esse fato de ser uma cultura isolada, dentro de uma ilha, uma ilha cultural, linguística. Por exemplo, em Pequena História da Literatura Brasileira (1919), de Ronald de Carvalho, isso aparece de forma muito clara. Ele parte de Atlântida, das ilhas imaginárias, da tradição clássica, até chegar nessa dimensão brasileira como ilha achada, ilha de reencontrar. Depois disso, podemos pensar em Jorge de Lima de "Fundação da Ilha" ou do título das crônicas do Drummond, Passeios na ilha, assim por diante. Essa é uma ideia forte dentro da cultura brasileira para reivindicar uma especificidade literária e reafirmar a identidade contra outros, ficando assim fora de qualquer corrupção por parte dos povos hispânicos.

A minha reflexão a partir dessa ideia de Brasil como ilha é também uma reflexão sobre qual é a função da ilha no imaginário europeu, passando pela Era Clássica, Idade Média. Ela é um lugar de compromisso em meio a incerteza e o medo do mar. Estou citando, na verdade, um trabalho muito interessante de um famoso historiador português que fala que a ilha está entre o medo do mar e a esperança de terra firme, de um continente, que ela é um espaço de mediação. Se lemos a Carta do Achamento a ilha, essa ilha grande onde é realizada a primeira missa, tem justamente essa função mediadora entre portugueses e indígenas.

A partir desse elemento insular eu comecei a pensar um pouco a cultura brasileira como a cultura que se articula em ilhas, em várias ilhas formando um arquipélago, um continente, uma dimensão que é, ao mesmo tempo, coerente e heterogênea, habitada por identidades múltiplas. Acho que essa riqueza é o que sempre me atraiu na literatura brasileira, esse elemento de heterogeneidade na substancial homogeneidade que existe, pelo menos, na língua. Se você pensa no meu país, a Itália, um morador do norte da Itália chega a não entender o italiano do sul. Enquanto aqui no Brasil há uma homogeneidade linguística e também, de certo ponto de vista, uma homogeneidade cultural. Ao mesmo tempo, há esse elemento de reinvindicação de uma identidade particular. É muito forte, por exemplo, aqui, no Rio Grande do Sul, a identidade gaúcha, que tem a ver com esse elemento mítico de criação de uma identidade à parte, de uma identidade parcial.

Sempre achei que a verdade está nesse conluio, nessa conjugação de diferentes. Por isso que tentei criar, imaginei ser possível criar, uma história que não seja uma história linear, mas que seja em rede, uma história enredada. "Rede" tem também a ver com narração. Tentei pensar de forma diferente. Eu não confio nesse esquema linear, apesar de muitas das histórias da literatura, também as canônicas, montarem uma história que parte da Carta do Achamento e chegam até os concretistas, por exemplo. É valido, pode ser válido do ponto de vista pedagógico, porque você tem uma coerência que pode expor, passar para os alunos. Mas não têm um efeito de passar a ideia de qual é a realidade brasileira, que é marcada por essas diferenças, por essas origens múltiplas.

BMB - As histórias da literatura, assim como seus respectivos manuais, têm uma presença forte no ensino da literatura no Brasil, para não dizer que são a base para os estudos literários no Ensino Médio. Esses manuais são lineares, consequenciais e teleológicos, diferentes em configuração, por exemplo, do trabalho que o sr. apresenta. De que forma a mudança da escrita da história da literatura pode afetar o seu ensino?

EFA - Tudo isso depende muito do auditório e do fruidor. Claro, um aluno do Ensino Médio busca uma visão desse tipo, que tenha uma lógica interna. Apresentar uma situação na qual a lógica temporal não funciona pode criar uma série de descompassos. Mas tudo isso não pode evitar que seja possível pensar a história da literatura, a história da cultura, de uma forma parcialmente ou totalmente diferente dessa. Vejo que, no âmbito geral da historiografia europeia, tudo isso está posto em questão, essa ideia de 
que existe uma linearidade histórica e cronológica. Eu costumo escrever "crono-lógica", com hífen, porque tem uma lógica temporal. Parece que o tempo em si tem uma lógica própria, mas na verdade o tempo não é isso, é uma dimensão sem logica.

Eu verifiquei que, na historiografia contemporânea e também na historiografia literária europeia, começa a ser considerada essa possibilidade de não ordenar os fatos em uma sequência, mas de considerar as coisas a partir do ponto de vista da sua dispersão. Nesse sentido, talvez o maior teórico depois de Nietzsche, e não por acaso, tudo isso sai em um artigo dele sobre a genealogia, foi Michael Foucault, que não falou mais em genealogia, mas em arqueologia. "Arqueologia" é um termo muito forte. $\mathrm{O}$ arqueólogo não vai tentar reconstruir, desvendar a origem. Ele vai reconstruindo aos poucos, vai conectando pedaços até construir o artefato. Acho que esse gesto arqueológico é extremamente importante. Não fui eu quem elaborei esse pensamento historicista, há vários teóricos da história que muito antes de mim pensaram de forma diferente, nova, não ligados a essa ideia da cronologia, do logos temporal. Claro, tudo isso é difícil de ser explicado para um aluno do Ensino Médio, porque as pessoas estão acostumadas a pensar o tempo como algo homogêneo, com uma dimensão como o espaço, que tem um início, um desenvolvimento e um fim. Ou pensar o tempo como contínuo. Acho que tudo isso pode funcionar do ponto de vista pedagógico, mas não do ponto de vista que eu chamaria de performativo, já que as coisas não são bem assim. Então, mantendo talvez essa ideia de uma história literária que seja consequencial, tentar mostrar também, sobretudo aos alunos do ensino superior, o tempo de uma forma diferente, não tradicional.

BMB - Mesmo que parcialmente, o sr. acredita que a figuração do Brasil como "ilha" reverbera na literatura contemporânea de alguma maneira, seja paradigmática ou tematicamente?

EFA - Claro que uma figura só não pode dar conta de toda realidade. Verifiquei que, na verdade, a ilha é uma das que muitas vezes aparece na literatura. Eu citei o caso de Jorge de Lima e de Drummond. São casos de que a ideia da ilha aparece de forma muito marcante. Acho a situação atual um pouco diferente, no sentido de que o processo de globalização da cultura levou a justamente a uma forma de homogeneidade que tem a ver também com o caráter de mercadoria do livro, que não é desses últimos anos, mas que, com certeza, na nossa época isso é fundamental. Não se pode imaginar que hoje seja possível escrever um livro só para não vender. Ele é escrito para ser vendido. "Globalização" significa também achatamento das diferenças, apagamento da heterogeneidade, e isso é um processo que talvez vai desmontar um pouco o esquema da insularidade no qual cada escritor é, em um certo sentido, uma espécie de ilha, porque o que funciona mais, do ponto de vista editorial, é a homogeneidade, e não a diferença. Nesse caso, tudo isso reverbera em um ponto de vista justamente editorial. Pesando nessas grandes conglomerações editoriais que aparecem aqui no Brasil agora, mas que são um fenômeno mundial, elas são, na verdade, multinacionais do livro.

Há um mundo em que o livro também é vendido, lido e fruído, como o caso da Amazon, uma grande livraria virtual, mundial. Você pode encontrar tudo, o que facilita, logicamente, o acesso aos livros, mas, ao mesmo tempo, deixa tudo isso com fronteiras mais fluidas, mais líquidas, de maneira que tudo é igual a tudo. Não sou, como se dizia em latim, laudator temporis acti, não sou um nostálgico dos séculos passados, porque vejo também o lado positivo das novidades. Recentemente, pediram para que eu escrevesse uma orelha de um romance de Patrick Modiano que eu não tinha em casa. Então eu encomendei o livro do Modiano na Amazon, um ebook, paguei por volta de 3 euros, chegou na hora, li o livro e escrevi a orelha. Isso é algo que até 10 anos atrás era impossível. Vejo também o lado positivo dessa circulação, mas, ao mesmo tempo, tudo isso condiciona o mercado. $\mathrm{O}$ mercado, por sua vez, condiciona os autores e a escrita literária. Sem falar do ensaísmo, que é quase uma dimensão a parte, sem falar da poesia que está sumindo do mercado.

Eu dei alguns exemplos na historiografia brasileira. Em geral, a imagem da ilha tem um papel importante. $\mathrm{Na}$ literatura do século XX aparece com frequência. Outro exemplo é o Euclides da Cunha, em Os sertões. No início, na parte que dedica à terra, ele faz a descrição do sertão e apresenta o Monte Santo, o cenário no qual vai se desenvolver esse drama, essa tragédia. Ele apresenta tudo isso como uma espécie de dimensão insular. Ele chega a dizer, forjando mais uma vez os dados geofísicos ou geológicos, que há autores que sustentam a ideia que aquela área do Brasil, na verdade, era uma ilha primitiva que foi se ligando ao continente. Por que isso? O Euclides está justamente tentando mais uma vez, assim como outros tentaram, desvendar uma especificidade nacional. Então esse elemento geológico, geofísico, se combina com o elemento antropológico, antrópico: o sertanejo como produto específico dessa dimensão espacial. O homem é marcado, determinado, pelo espaço físico onde ele existe. Do ponto de vista da gênese da identidade brasileira, é um lugar à parte no qual está se formando esse novo homem brasileiro, ou essa "raça", como antigamente se chamava, com essa ideia de que ali está escondido alguma coisa. Ele precisava de uma dimensão à parte. $\mathrm{O}$ título é um dado interessante, e não é verdade que ele inventou esse plural "sertões", porque ele existia antes de Euclides. Ele tentou selecionar, é verdade, de dentro dessa multiplicidade de 
sertões, aquele "sertão", que ele imagina como ilha, na qual está surgindo alguma coisa de específico. O Euclides da Cunha é mais uma demonstração de como essa ideia de ilha se perpetuou.

Eu poderia falar também do Guimarães Rosa o contrário. Na verdade, desde o início, na fala de Riobaldo, o sertão é uma dimensão sem limite, chega a dizer que "o sertão é dentro da gente". Mas, ao mesmo tempo, ele apresenta essa dimensão como específica, na qual as coisas se dão de uma forma diferente em relação a outros lugares, outros espaços. Embora tudo isso tenha um eco universal, com os elementos da luta entre bem e o mal, deus e o diabo, o amor sacro e o amor profano, tudo isso tem um valor específico dentro dessa dimensão que é a dimensão sertaneja do sertão, mas que se abre para o mundo, para essa dimensão universal através desse elemento "veredas", nesse título tão misterioso que é Grande sertão, e dois pontos, veredas. É como se esse elemento plural justificasse a existência e desse um sentido ao "Grande sertão".

Recebido: 28 de abril de 2016 Aprovado: 20 de junho de 2016 Contato: brunomazolini@gmail.com 